\title{
Factors affecting the foraging behaviour of the European shag: implications for seabird tracking studies
}

\author{
L. M. Soanes · J. P. Y. Arnould · S. G. Dodd · \\ G. Milligan · J. A. Green
}

Received: 19 August 2013 / Accepted: 8 March 2014 / Published online: 3 April 2014

(C) The Author(s) 2014. This article is published with open access at Springerlink.com

\begin{abstract}
Seabird tracking has become an ever more popular tool to aid environmental procedures such as the designation of marine protected areas and environmental impact assessments. However, samples used are usually small and little consideration is given to experimental design and sampling protocol. European shags Phalacrocorax aristotelis were tracked using GPS technology over three breeding seasons and the following foraging trip characteristics: trip duration, trip distance, maximum distance travelled from the colony, size of area used and direction travelled from colony were determined for each foraging trip. The effect of sex, year of study, breeding site, number and age of chicks and the timing of tracking on foraging behaviour were investigated using a General Estimation Equation model. A range of sampling scenarios reflecting likely field sampling were also tested to compare how foraging behaviour differed depending on composition of the sample of birds tracked. Trip distance, trip duration, maximum distance travelled and size of area used were all significantly affected by the breeding site, and the number of chicks a tracked adult was raising. The effect of sex was also seen when examining trip distance, trip duration and
\end{abstract}

Communicated by S. Garthe.

L. M. Soanes $(\varangle) \cdot$ G. Milligan · J. A. Green

School of Environmental Sciences, University of Liverpool, Liverpool L69 3GP, UK

e-mail: louise.soanes@liv.ac.uk

J. P. Y. Arnould

School of Life and Environmental Sciences, Deakin University, Burwood 3215, Australia

S. G. Dodd

Royal Society for the Protection of Birds, North Wales Office,

Bangor LL57 4FD, UK the maximum distance travelled. The direction travelled on a foraging trip was also significantly affected by breeding site. This study highlights the importance of sampling regime and the influence that year, sex, age, number of chicks and breeding site can have on the foraging trip characteristics for this coastal feeding seabird. Given the logistical and financial constraints in tracking large numbers of individuals, this study identifies the need for researchers to consider the composition of their study sample to ensure any identified foraging areas are as representative as possible of the whole colony's foraging area.

\section{Introduction}

In recent years, the number of seabird tracking studies using global positioning system data loggers, satellite transmitters and geolocators has increased substantially due to the availability of cheaper and smaller technologies, adding greatly to our understanding of seabird behaviour and ecology (Evans et al. 2013; Hazen et al. 2012; Burger and Shaffer 2008). A range of seabird species have now been tracked, ranging from the 150-g Thin-billed prion Pachyptila belcheri (Quillfeldt et al. 2012) to the 12-kg Wandering albatross Diomedea exulans (Shaffer et al. 2005; Gremillet et al. 2012). These studies have been used to inform the designation and effectiveness of marine protected areas (e.g. BirdLife 2010; Harris et al. 2007; Hyrenbach et al. 2006), to provide data for environmental impact assessments (e.g. Perrow et al. 2006; Soanes et al. 2012), to examine the effects of environmental change (e.g. Durant et al. 2009; Wanless et al. 2007; Wilson et al. 2002) and to assess changes in fishery practices (e.g. Bugoni et al. 2009; Copello and Quintana 2009) (Table 1). However, the logistical and financial constraints of working at seabird 


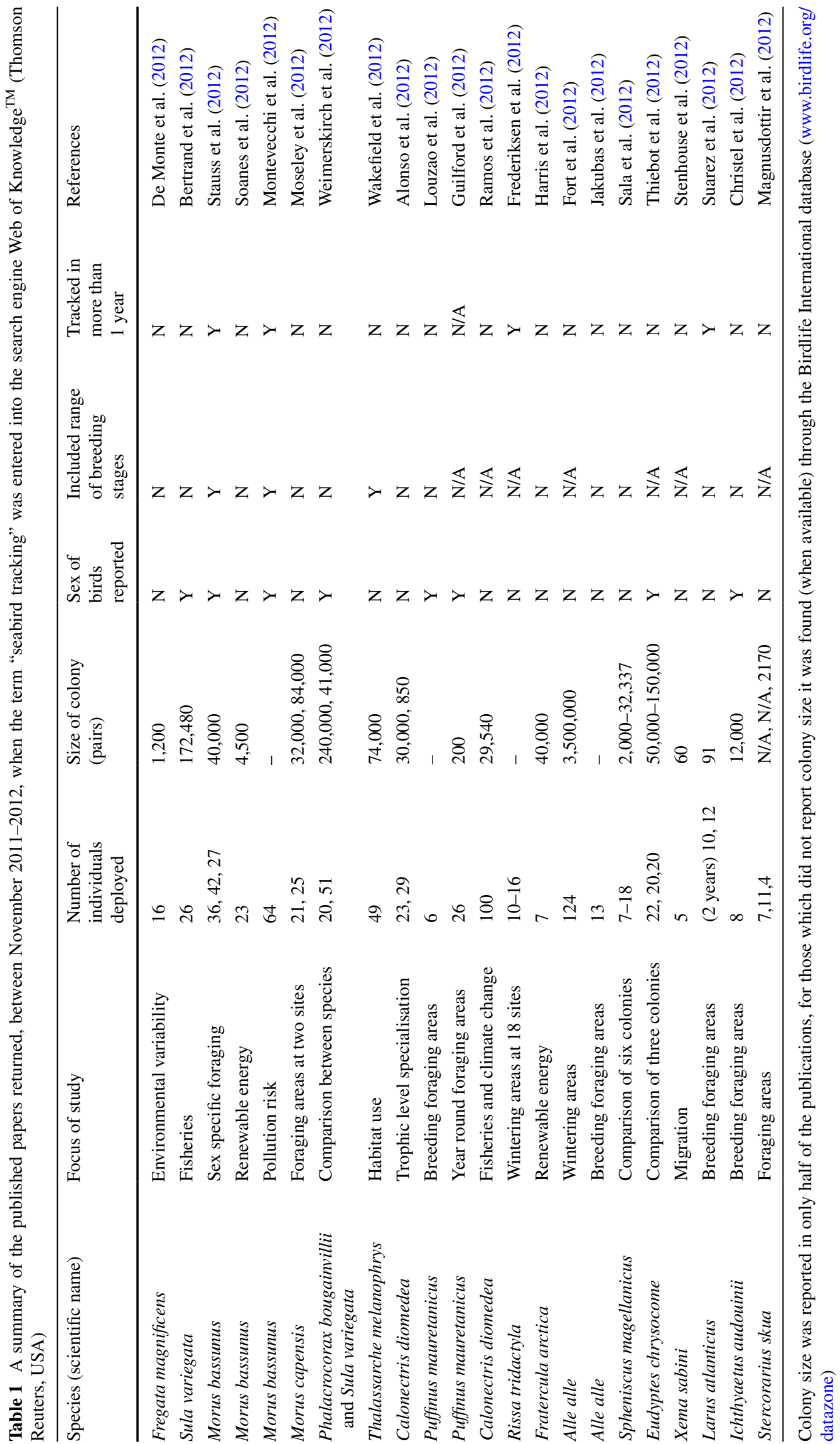


colonies often means that samples of individuals used in tracking studies may fail to properly represent the traits of the population. A review of recent literature (Table 1) revealed that seabird tracking studies used a mean sample size of 29 individuals in each year of study (range 4-124, median $=23, n=33$ ). Sample size in these studies were found to represent a mean of only $1.4 \%$ of the total colony size (range $0.001-25 \%, n=30$ colonies), which is somewhat biased by the study of Stenhouse et al. (2012) who tracked 30 individuals from a colony of 65 pairs. If this study is excluded from the sample, we find that the sample size used at the remaining colonies represented only $0.7 \%$ (range $0.001-6.6 \%, n=29$ colonies) of the study colony. Birds were tracked for more than one field season in just four out of the 22 of the studies, eight of the studies reported the sex of tracked birds, and three covered a range of breeding stages (e.g. incubating and chick-rearing individuals). Whilst the reporting of these factors may not be applicable to all studies (e.g. for wintering area distributions). These factors are likely to influence the results of tracking studies undertaken during the breeding season when only small samples are used.

These limited sampling regimes are likely to fail to adequately represent population-level characteristics. This is due in part, to the known variability in seabird foraging behaviour due to effects such as inter-individual differences caused by underlying physiology (Biro and Stamps 2010; Sommerfeld et al. 2013), sex-related differences (Weimerskirch et al. 2009; Pinet et al. 2012), age and experience (Daunt et al. 2007), environmental factors (Chivers et al. 2012), location of breeding site (Hipfner et al. 2007), stage of breeding clutch size and size of colony (Wakefield et al. 2013). Soanes et al. (2013) highlight the need for researchers to explore and accept the limitations of their data sets before drawing conclusions on the location and extent of a whole colony's important foraging areas by considering the number of individuals and foraging trips included in a sample. Therefore, whilst it may not be possible to sample a large number of individuals from any particular colony, we should ensure that the individuals that are sampled are as representative as possible of the whole study population.

In this study, we examined the effect of a range of factors on the foraging behaviour of European shags Phalacrocorax aristotelis breeding at Puffin Island, Wales, Great Britain a designated special protected area (SPA). The European shag is a good model species for testing these interactions given that they are a dimorphic species and can easily be sexed by their calls (Snow 1963). During breeding, they exhibit variability in the number of eggs laid per female (ranging from 1 to 4 eggs) and in chick-rearing success with not all chicks surviving to fledging. Furthermore, the distribution of breeding sites at this study colony can be classified into separate "sub-colonies" and 3 years worth of tracking data was collected from this species at this site allowing the effect of year on foraging behaviour to be investigated. The European shag is considered an Amber listed species in Europe (Eaton et al. 2009) and at 494 breeding pairs the Puffin Island colony is the largest population in Wales (Goddard 2010). This species has also been identified as having good potential for acting as a reliable ecological indicator on the state of the marine environment (Fortin et al. 2013). The effects of year, sex, age of chicks, timing of tracking, number of chicks being raised and the breeding site on foraging trip distance, duration, maximum distance travelled from the colony and the size of the area used were tested with the aim of determining which, if any, are the most important factors to consider when planning and undertaking a seabird tracking study. We then simulated different realistic sampling regimes to evaluate how sample selection can influence conclusions on apparent foraging characteristics.

\section{Methods}

Field methods

European Shags (from here on referred to as "shags"), breeding on Puffin Island, Great Britain $\left(53.3^{\circ} \mathrm{N}, 4.0^{\circ} \mathrm{W}\right)$ were tracked using IgotU GT-120 GPS data loggers (Mobile Action, Taiwan) over three consecutive breeding seasons (2010-2012). Birds were caught whilst brooding chicks at their nests using a crooked pole. A total of 28, 31 and 25 individuals were instrumented in 2010, 2011 and 2012, respectively, 11 individuals were tracked in more than 1 year. Loggers were deployed between the 9th May and 18th June of each year (which represents the main chick-rearing period for this species) and samples represented males and females, individuals breeding at three different sites, with different numbers of chicks at the time of tracking, and with varying ages of chicks (from 1 to 35 days) (Table 2). Loggers were attached to the back feathers with waterproof Tesa ${ }^{\circledR}$ Extra power tape (Wilson et al. 1997) and weighed $15 \mathrm{~g}$ when packaged, which equates to $<1 \%$ of a shags body weight. The battery life of these loggers was 5-6 days when set to record a location every 2 min.

Regular visits to nests before, during and after tracking allowed us to estimate the age of the chicks and allowed us to monitor the productivity of the nests which were compared to control nests each year to assess any detrimental effects of tracking. The number of chicks that reached approximately 30-35 days old per nest was recorded (this is the age when they became mobile and were difficult to assign to individual nests) as an estimate of the productivity of each nest. A Kruskal-Wallis one-way 
Table 2 Sample sizes used for each explanatory variable included in the General Estimation Equation model

\begin{tabular}{lcc}
\hline & Sample size & $\begin{array}{l}\text { Number of } \\
\text { foraging trips }\end{array}$ \\
\hline Sex & 28 & 302 \\
Males & 29 & 261 \\
Females & & \\
Site & 32 & 293 \\
Ledge & 17 & 197 \\
North side & 8 & 73 \\
Beach & & \\
Year & 20 & 174 \\
2010 & 16 & 161 \\
2011 & 21 & 228 \\
2012 & & \\
Number of chicks & 7 & 59 \\
1 Chick & 20 & 313 \\
2 Chicks & 30 & 563 \\
3 Chicks & 57 & \\
Total & &
\end{tabular}

analysis was conducted on this productivity data to assess site differences.

\section{Tracking data}

The GPS devices did not always record a position every $120 \mathrm{~s}$ as programmed to do so, in part due to the diving activity of shags. This may provide a biased sample of the spatial distribution of foraging activity (McLeay et al. 2010), and so GPS fixes were interpolated to every $10 \mathrm{~s}$ using the software R (R Development Core Team 2011) with the package "trip" (Sumner 2012). This package was also used to calculate the area covered on each foraging trip by calculating the time spent in a pre-defined grid of $1 \times 1 \mathrm{~km}$ cells surrounding the breeding colony. The number of cells used on each trip was used to represent the size of the area $\left(\mathrm{km}^{2}\right)$ covered on each foraging trip. Total trip distance $(\mathrm{km})$, trip duration $(\mathrm{min})$, the maximum distance travelled from the colony $(\mathrm{km})$ and the direction travelled were also calculated for each trip.

\section{Statistical methods}

We tested the effects of a range of categorical and continuous explanatory variables including: (1) sex of the bird, (2) number of chicks, (3) age of chicks at the time of tracking, (4) location of nest on the island, (5) date that tracking was undertaken and (6) year of tracking on the five foraging trip response variables described above. Our aim was to determine which, if any, might account for the variation in foraging behaviour that was observed between individuals. Total trip distance, trip duration and the maximum trip distance were $l n$-transformed. Generalised estimation equations (GEEs) (Liang and Zeger 1986) were used in the analysis; this allowed for compound correlation structures to be specified for each individual, in order to account for withinindividual correlation. They also are more suitable than the more commonly used General Linear Models for understanding population effects rather than individual-specific effects. The models were implemented in the "geepack" version 1.1-6 package (Højsgaard et al. 2012) in the $R$ software environment (R Development Core Team 2011). All models incorporated the same terms consisting of sex, number of chicks, year of study and location of breeding site as fixed factors and the numeric factors of age of chicks at time of tracking and the number of days into the tracking season that tracking was undertaken (days from 1st April of each year). The model outputs were analysed using one-way ANOVAs, and significant terms at $p<0.05$ level were then submitted to post hoc Tukey comparison tests to ascertain within-factor differences. In addition to the main model, the circular statistic software Oriana (Kovach Computing Services, UK) for windows and the WatsonWilliams $F$ test (Batschelet 1981) were also used to analyse any differences in the direction travelled in relation to the explanatory variables. In all analyses, a significance level of $p<0.05$ was applied.

Maps of time spent in pre-defined grid cells of $1 \times 1 \mathrm{~km}$ were plotted to compare use of space by shags around the colony for the explanatory variables that were found to be significant after the GEE model was run (those with a $p$ value $<0.05)$. Home-range areas were represented as the actual time spent in a pre-defined grid of $1 \times 1 \mathrm{~km}$ cells surrounding the breeding colony (Page et al. 2006). The $1 \times 1 \mathrm{~km}$ cells that the animals spent $100 \%$ of their time was used to represent their area of active use and the cells that the animals spent $50 \%$ of their time (after ranking for frequency of use was) used to represent their core-foraging areas (Casper et al. 2010; Soanes et al. 2013).

A range of sampling scenarios to represent commonly implemented field sampling campaigns was also simulated and compared. Likely scenarios were selected by reviewing the literature for tracking studies of the European shag and other closely related species. For example, Cook et al. (2007) tracked samples of 8, 5 and 16 chick-rearing Cape cormorants Phalacrocorax capensis (from three colonies) representing both sexes over a 7-week period, Quintana et al. (2011) tracked 27 male and 26 female Imperial cormorants Phalacrocorax atriceps over three breeding seasons but only during the first 2 weeks of chick-rearing, Kotzerka et al. (2011) tracked 14 chick-rearing male Pelagic cormorant Phalacrocorax pelagicus over a 6-week period and Watanabe et al. (2011) tracked 26 (20 males and 
Fig. 1 Maps showing a location of Puffin Island, Great Britain and the foraging trips recorded from European shags breeding in b 2010 c 2011 and d 2012
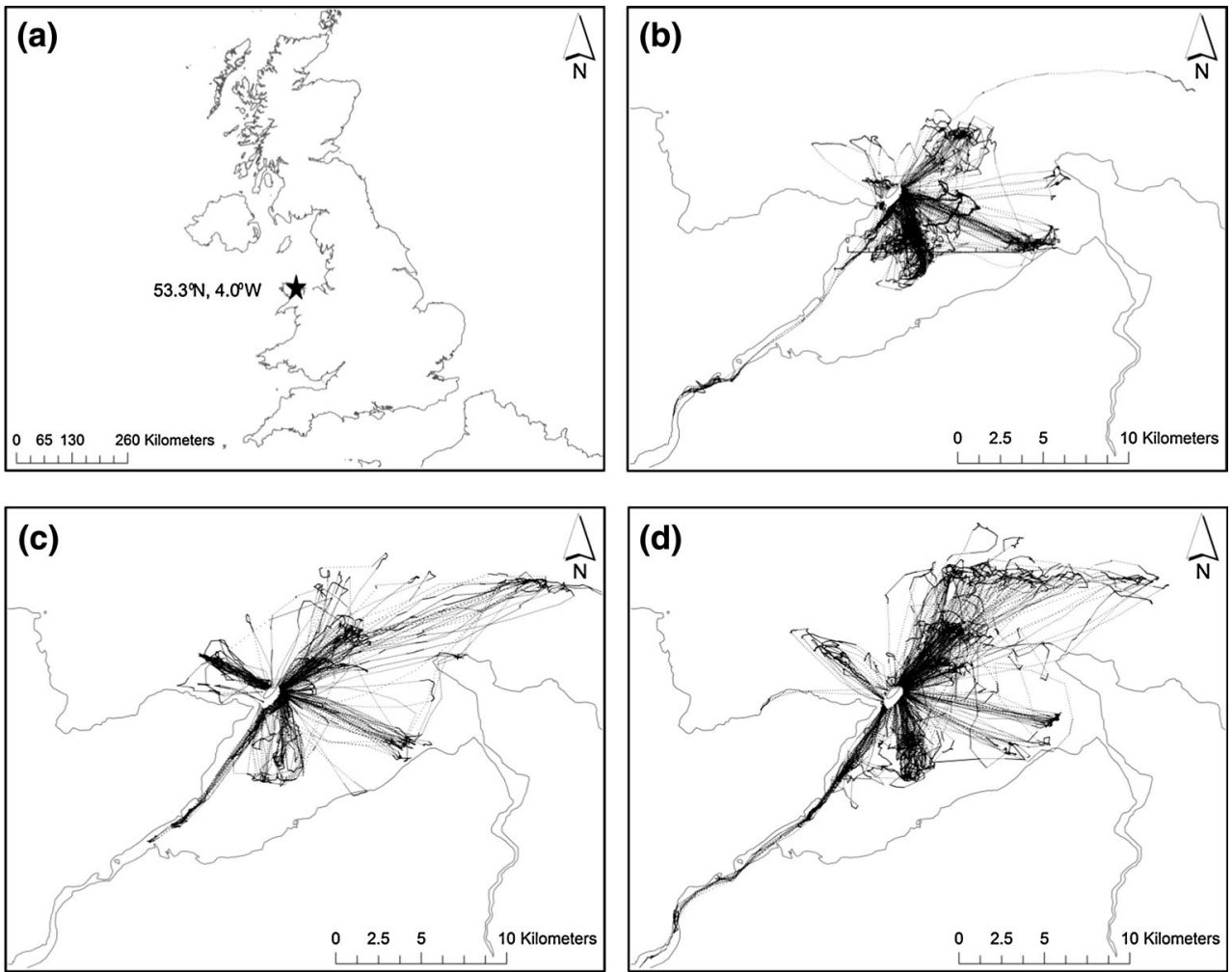

six female) Kerguelen cormorants Phalacrocorax verrucosus which were rearing one or two chicks only. Eight sampling scenarios were devised; (A1) shags tracked between the 1-14 May 2010 versus (A2) shags tracked between the 15 May-14 June 2010; (B1) shags breeding at the ledge site in 2010 versus (B2) shags breeding at the North side and beach sites in 2010; (C1) shags with chicks under 14 days old in 2011 versus (C2) shags with chicks over 14 days old in 2011 and finally (D1) all shags tracked in 2011 compared with (D2) all shags tracked in 2012. These samples included 6-11 individuals (29-181 foraging trips) reflecting commonly used field sample sizes. Differences between the sampling scenarios were tested using a twosample $t$ test, (significance level of $p<0.05$ ).

\section{Results}

Each year, 18-21 loggers ( 20 in 2010, 18 in 2011 and 21 in 2012) were retrieved from shags breeding on Puffin Island. Two loggers in 2011 were retrieved waterlogged and all others were lost by the birds before they could be recaptured. Data from a mean of $9.7( \pm 0.6 \mathrm{SEM})$ foraging trips were obtained per individual (range 2-20 trips). Total foraging trip distance ranged from 0.5 to $58 \mathrm{~km}$, and birds travelled $0.3-30 \mathrm{~km}$ from the colony. Trip duration was between 10 and $439 \mathrm{~min}$. All foraging trips recorded over all years are shown in Fig. 1 .
Productivity of study nests was recorded as $1.8,1.5$, and 2.6 chicks per nest in 2010, 2011 and 2012, respectively. This compared favourably to $1.2,1.4$ and 1.8 chicks per nest recorded in control nests in each year. The number of chicks reaching 30-35 days old in each nest in our study was compared between each breeding site using a KruskalWallis one-way analysis on ranks. No significant differences were found in the number of chicks raised between the sites $\left(H_{d f=2}=2.971, p=0.226\right)$.

\section{Trip distance}

Total trip distance was found to differ significantly between the sexes $(F=13.59, d f=1, p<0.001)$, with males travelling shorter distances (mean $8.4 \pm 0.5$, range $0.5-40 \mathrm{~km}$ ) than females (mean $11.1 \pm 0.5$, range 0.9-58 km). Significant differences ( $F=4.8, d f=2, p=0.022)$ were also observed in total trip distance between individuals raising one chick (mean $9.0 \pm 0.8$, range $0.9-28 \mathrm{~km}$ ) and individuals raising three chicks (mean $10.7 \pm 0.5$, range 0.8-58 km) (Table 3). Significant differences between all breeding sites were also observed $(F=34.2, d f=2, p<0.05)$ with shags breeding at the ledge site, exhibiting the greatest trip distance (mean $11.6 \pm 0.6$, range $0.8-58 \mathrm{~km}$ ) compared with those breeding at the North site (mean $9.4 \pm 0.6$, range $1-48 \mathrm{~km}$ ) and those breeding at the beach site (mean $4.4 \pm 0.6$, range $0.5-49 \mathrm{~km}$ ). The timing of tracking during the breeding season also had a significant effect on foraging trip distance ( $p=0.03$ ) (Fig. 2). 
Table 3 Summary of mean estimates $( \pm$ SEM) by response variable and explanatory factor

\begin{tabular}{|c|c|c|c|c|c|c|c|c|c|c|c|c|}
\hline & \multicolumn{3}{|c|}{ Trip distance } & \multicolumn{3}{|c|}{ Trip duration } & \multicolumn{3}{|c|}{ Maximum distance } & \multicolumn{3}{|l|}{ Area used } \\
\hline & Mean & Contrast & $p$ value & Mean & Contrast & $p$ value & Mean & Contrast & $p$ value & Mean & Contrast & $p$ value \\
\hline \multicolumn{13}{|l|}{ Sex } \\
\hline Female & $11.1 \pm 0.5$ & $\mathrm{~F}: \mathrm{M}$ & $<0.001$ & $94.6 \pm 4.6$ & $\mathrm{~F}: \mathrm{M}$ & 0.04 & $4.6 \pm 0.2$ & $\mathrm{~F}: \mathrm{M}$ & 0.001 & $12.6 \pm 0.60$ & $\mathrm{~F}: \mathrm{M}$ & 0.09 \\
\hline Male & $8.4 \pm 0.5$ & & & $75.2 \pm 2.9$ & & & $3.6 \pm 0.2$ & & & $11.3 \pm 0.5$ & & \\
\hline \multicolumn{13}{|l|}{ Chicks } \\
\hline One & $9.0 \pm 0.8$ & $1: 2$ & 0.44 & $75.2 \pm 5.1$ & $1: 2$ & 0.10 & $3.7 \pm 0.3$ & $1: 2$ & 0.323 & $10.7 \pm 0.8$ & $1: 2$ & 0.23 \\
\hline Two & $8.1 \pm 0.6$ & $1: 3$ & 0.02 & $85.6 \pm 4.2$ & $1: 3$ & 0.004 & $3.5 \pm 0.3$ & $1: 3$ & 0.016 & $10.8 \pm 0.6$ & $1: 3$ & 0.01 \\
\hline Three & $10.7 \pm 0.5$ & $2: 3$ & 0.10 & $94.6 \pm 3.8$ & $2: 3$ & 0.26 & $4.5 \pm 0.2$ & $2: 3$ & 0.162 & $12.9 \pm 0.6$ & $2: 3$ & 0.15 \\
\hline \multicolumn{13}{|l|}{ Site } \\
\hline Beach & $4.4 \pm 0.6$ & $\mathrm{~L}: \mathrm{B}$ & $<0.001$ & $78.3 \pm 6.0$ & L:B & 0.11 & $1.8 \pm 0.3$ & L:B & $<0.001$ & $7.28 \pm 0.9$ & $\mathrm{~L}: \mathrm{B}$ & $<0.001$ \\
\hline Ledge & $11.6 \pm 0.6$ & $\mathrm{~N}: \mathrm{B}$ & $<0.001$ & $93.7 \pm 3.7$ & $\mathrm{~N}: \mathrm{B}$ & 0.92 & $4.9 \pm 0.2$ & $\mathrm{~N}: \mathrm{B}$ & $<0.001$ & $13.5 \pm 0.6$ & $\mathrm{~N}: \mathrm{B}$ & 0.02 \\
\hline North side & $9.4 \pm 0.6$ & B:N & 0.003 & $84.8 \pm 4.1$ & B:N & 0.08 & $4.1 \pm 0.08$ & B:N & 0.0010 & $11.1 \pm 0.6$ & $\mathrm{~B}: \mathrm{N}$ & 0.005 \\
\hline \multicolumn{13}{|l|}{ Year } \\
\hline 2010 & $8.0 \pm 0.6$ & 2010:2011 & 0.91 & $90.0 \pm 5.2$ & 2010:2011 & 0.02 & $3.2 \pm 0.2$ & 2010:2011 & 0.370 & $10.6 \pm 0.6$ & 2010:2011 & 0.76 \\
\hline 2011 & $10.1 \pm 0.7$ & 2010:2012 & 0.38 & $77.5 \pm 3.0$ & 2010:2012 & 0.97 & $4.4 \pm 0.3$ & 2010:2012 & 0.072 & $12.4 \pm 0.9$ & 2010:2012 & 0.72 \\
\hline 2012 & $10.2 \pm 0.6$ & 2011:2012 & 0.67 & $95.6 \pm 4.7$ & 2011:2012 & 0.02 & $4.4 \pm 0.3$ & 2011:2012 & 0.754 & $12.3 \pm 0.6$ & 2011:2012 & 1 \\
\hline & Slope & & & & & & Slope & & & Slope & & \\
\hline Days & -0.009 & & 0.03 & -0.27 & & 0.054 & -0.013 & & 0.361 & -0.12 & & 0.40 \\
\hline Age & -0.007 & & 0.67 & 0.003 & & 0.049 & -0.01 & & 0.052 & -0.11 & & 0.99 \\
\hline
\end{tabular}

$p$ values indicate significance of ANOVA test of the variables stated in the contrast column. Bold values $=$ significant $p$ values

Trip duration

Trip duration was sensitive to the year of study with significant differences $(F=5.9, d f=2, p<0.02)$ observed in trip duration between 2010 (mean $90 \pm 5$, range 13-407 min) and 2011 (mean $76 \pm 3$, range 14-283 $\mathrm{min}$ ), and between 2011 and 2012 (mean $96 \pm 5$, range 10-439 min) (Fig. 2). Sex also significantly affected trip duration $(F=2.74$, $d f=1, p=0.04)$, with males having a shorter trip duration (mean $72.5 \pm 3$, range 10-408 min) than females (mean $94.6 \pm 5$, range 13-429 $\mathrm{min}$ ). Individuals raising one chick at the time of tracking had significantly $(F=5.2$, $d f=2, p=0.0004$ ) shorter trip durations (mean $75 \pm 5$, range 19-240 $\mathrm{min}$ ) than those raising three chicks (mean $95 \pm 4$, range 13-439 $\mathrm{min}$ ). The age of chicks also significantly increased trip duration $(F=8.0, d f=1, p=0.049)$ (Table 3).

Maximum distance travelled

Maximum distance travelled was also found to be significantly different between the sexes $(F=13.59, d f=2$, $p=0.001$ ) with females travelling further (mean $4.6 \pm 0.2$, range $0.3-23 \mathrm{~km}$ ) than males (mean $3.6 \pm 0.2$, range $0.2-$ $19 \mathrm{~km}$ ) (Fig. 2). Significant differences $(F=4.8, d f=2$, $p=0.016)$ were also observed in the maximum distance travelled between individuals raising one chick (mean $3.7 \pm 0.3$, range $0.3-10 \mathrm{~km}$ ) compared with individuals raising three chicks (mean $4.5 \pm 0.2$, range $0.3-23 \mathrm{~km}$ ) and between all breeding sites $(F=34.2, d f=2, p<0.001)$ with shags breeding at the ledge site exhibiting the greatest maximum distance travelled (mean $4.9 \pm 0.2$, range 0.3-19 km) compared with those breeding at the North site (mean $4.1 \pm 0.08$, range $0.3-23 \mathrm{~km}$ ) and those breeding at the beach site (mean $1.8 \pm 0.3,0.2-20 \mathrm{~km}$ ) (Table 3 ).

Area used

The area used $\left(\mathrm{km}^{2}\right)$ on each foraging trip was sensitive to breeding site with significant differences found between all sites $(F=15.3, d f=2, \mathrm{p}<0.05)$ (Table 3$)$. Those breeding at the beach site foraged over a smaller area (mean $7.3 \pm 0.9$, range $1-35 \mathrm{~km}^{2}$ ) compared with those breeding at the North site (mean $11.1 \pm 0.6,1-40 \mathrm{~km}^{2}$ ) and the ledge site (mean $13.5 \pm 0.6$, range $1-55 \mathrm{~km}^{2}$ ) (Fig. 2). Significant differences in foraging $(F=5.22, d f=2, p<0.005)$ area were also observed between shags rearing one chick (mean $10.7 \pm 0.8$, range $1-27 \mathrm{~km}^{2}$ ) compared with those rearing three chicks (mean $12.9 \pm 0.6,1-49 \mathrm{~km}^{2}$ ) (Fig. 3). Maps of time spent in $1 \mathrm{~km}^{2}$ cells revealed different areas of use for shags rearing one chick compared with those rearing three chicks and for shags breeding at the three different sites (Figs. 3, 4).

\section{Direction travelled}

For direction travelled, significant differences were found between sites $\left(F_{2,520}=78.5, p<0.001\right)$. Pair-wise 
Fig. 2 Examples of the mean differences in the foraging trip response variables significantly affected by breeding site, year of study, sex and the number of chicks an individual was raising
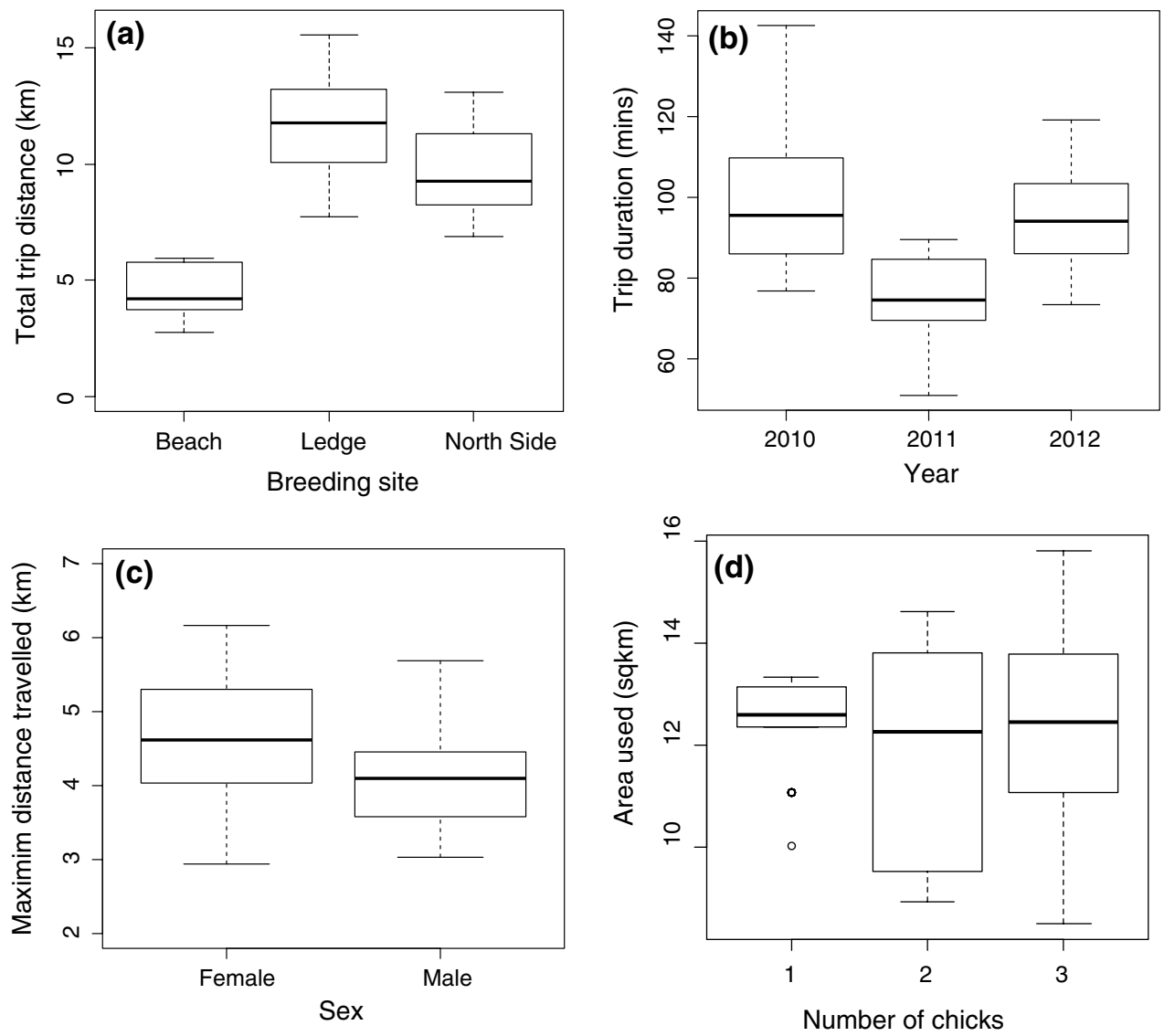

comparisons revealed significant differences between the beach and North site $\left(F_{250}=139.7, p<0.001\right)$; beach and ledge $\left(F_{342}=140.6, p<0.001\right)$ and ledge and North site $\left(F_{448}=17.0, p<0.001\right)$. Trips originating from the beach site travelled a mean bearing of $22.6^{\circ}$ (SD 73.3 $)$, from the North side site $70.3^{\circ}$ (SD 80.8 $)$ and from the ledge site $100.5^{\circ}$ (SD 53.8 $)$ (Fig. 5). Significant differences $(p<0.05)$ were not observed in the direction travelled between males and females, between years or between individuals which were raising one, two or three chicks at the time of tracking.

\section{Effect of sampling regime}

Different sampling regimes produced different estimates for all foraging trip response variables (Fig. 6), in some cases predicting a difference of up to $50 \%$ for the foraging trip parameters. Each pair of sampling regimes induced at least one significant difference in a foraging trip response variable. For example, using a sample from 2010 tracked over a 3-week period between mid May to the first week of June produced a foraging trip distance of $9.8(\mathrm{SE} \pm 0.7)$ $\mathrm{km}$ compared with $13.2( \pm 1.1) \mathrm{km}$ for a sample tracked in the same year but earlier in the season (Fig. 5, A1 vs.
A2). Tracking individuals breeding at the ledge site in 2010 produced a foraging area estimate of $13.8( \pm 0.8) \mathrm{km}^{2}$ compared with $10.5( \pm 0.95) \mathrm{km}^{2}$ when sampling individuals only from the North and beach sites (Fig. 5, B1 vs. B2). Similarly, a sample tracked in 2011 with chicks under 14 days old produced a maximum foraging trip distance of $8.8( \pm 0.97) \mathrm{km}$ compared with $5.1( \pm 0.38) \mathrm{km}$ from a sample of individuals tracked in the same year but that was composed only of individuals with chicks over 14 days old (Fig. 5, C1 vs. C2). Trip duration was found to be greater by $26 \mathrm{~min}$ in $2012(116 \pm 15 \mathrm{~min})$ compared with trip duration in 2011 (82 $\pm 14 \mathrm{~min})$ (Fig. 5, D1 vs. D2).

\section{Discussion}

This is one of the few published studies reporting the foraging behaviour of the European shag determined using GPS technology. The European shag is widespread throughout north-western and southern Europe, where more than $75 \%$ of the global population is found. In the United Kingdom, this species breeds on coastal sites, mainly in the north and west, where over half their population is found at fewer than ten sites, making this an Amber listed species (Eaton 

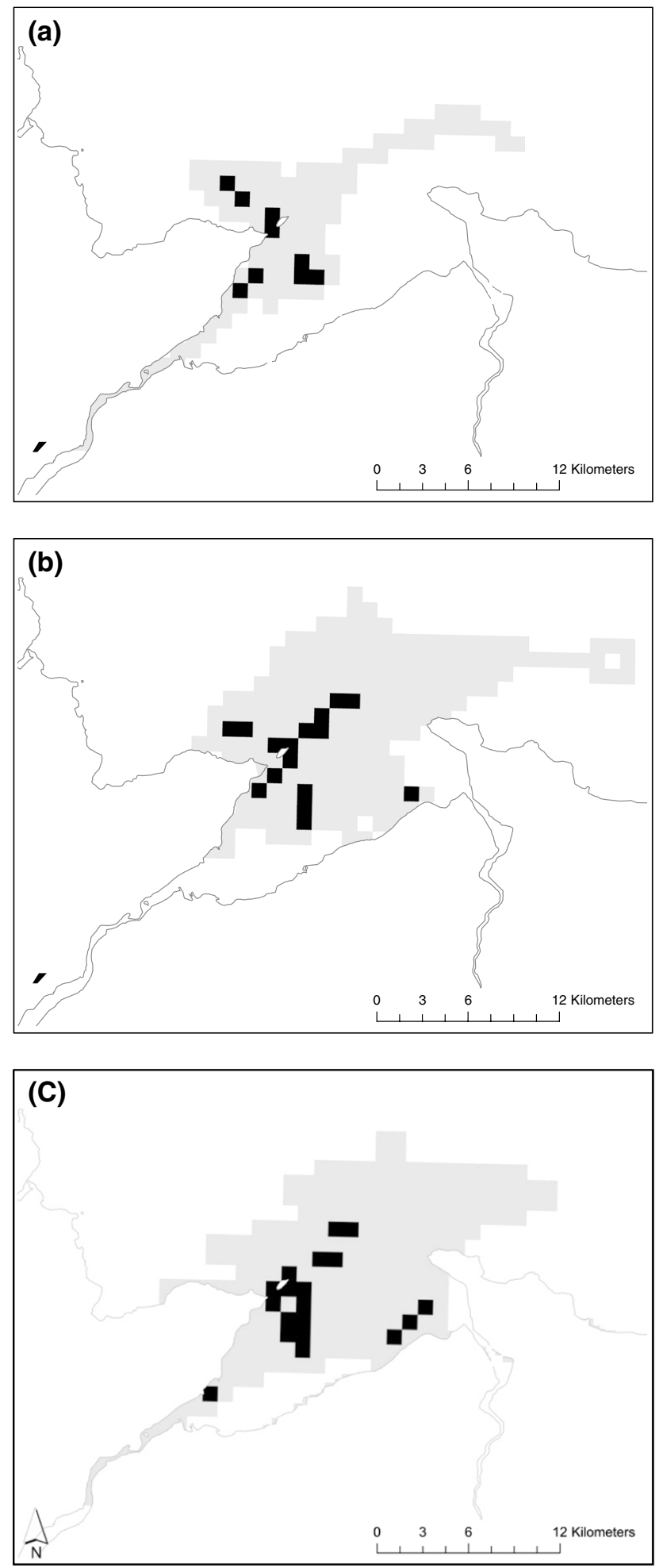

Fig. 3 Time spent in pre-defined $1 \times 1 \mathrm{~km}$ cells for a shags breeding at the beach site. b Shags breeding at the North site and $\mathbf{c}$ shags breeding at the ledge. Black squares indicate where $50 \%$ of all time was spent; grey squares indicate where $100 \%$ of time was spent
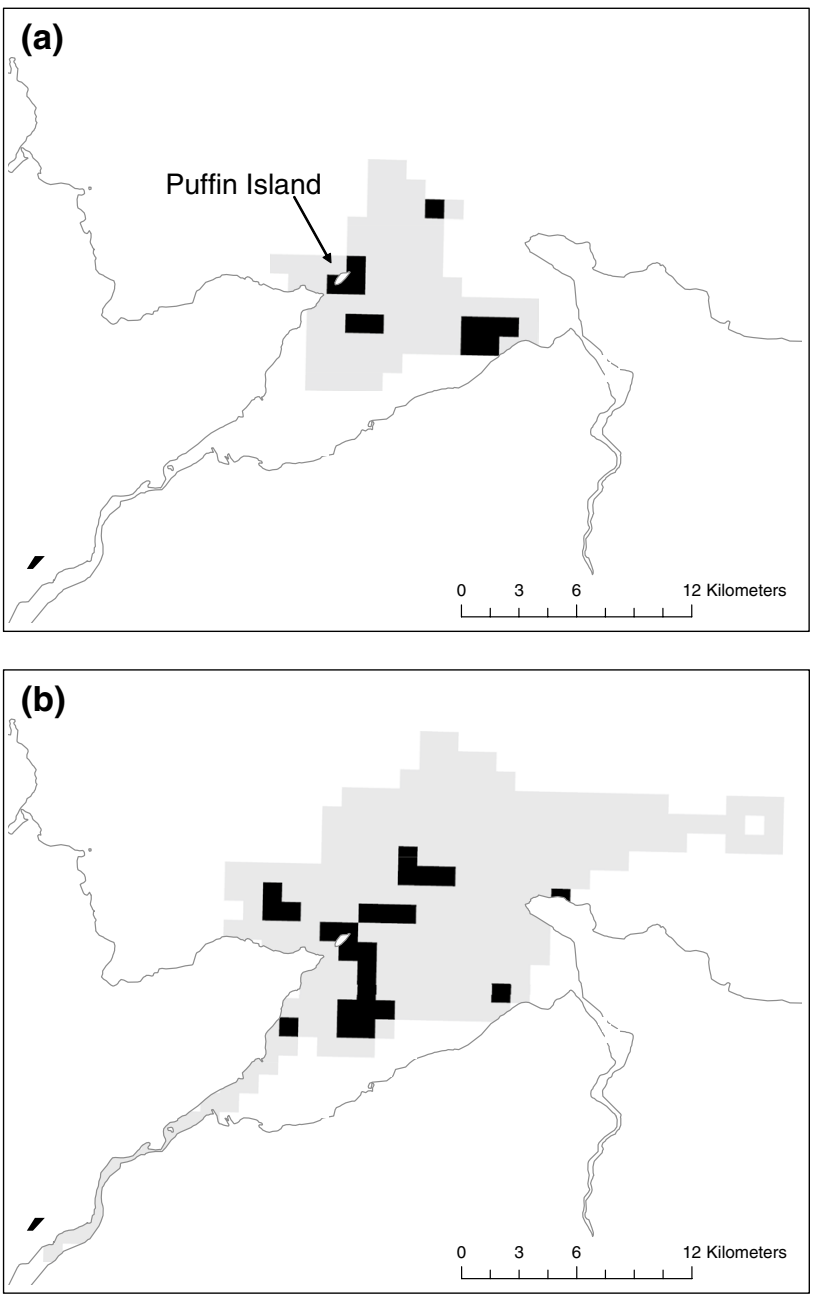

Fig. 4 Time spent in pre-defined $1 \times 1 \mathrm{~km}$ cells for a shags with one chick. b Shags with three chicks. Black squares indicate where $50 \%$ of all time was spent; grey squares indicate where $100 \%$ of time was spent

et al. 2009). Previous studies on this species have used observations at sea and radio telemetry techniques (Wanless et al. 1991, 1998; Elkins and Williams 1974), and one other recent GPS tracking study of this species has been reported from a study site in France (Fortin et al. 2013). Understanding the foraging behaviour of the European shag is important, particularly with the anticipated rise in offshore marine renewable developments occurring in European waters (RenewableUK 2011). Given the coastal nature of this species, it is likely to be more susceptible to offshore marine developments (Langton et al. 2011).

Intraspecific variation in foraging ecology has previously been observed for other central-place foragers. For example, Austin et al. (2004) found wide variation in the foraging ecology of individual Grey seals Halichoerus 
Fig. 5 The direction travelled the three sites on the island (beach, ledge and North breeding sites) on each foraging trip made at
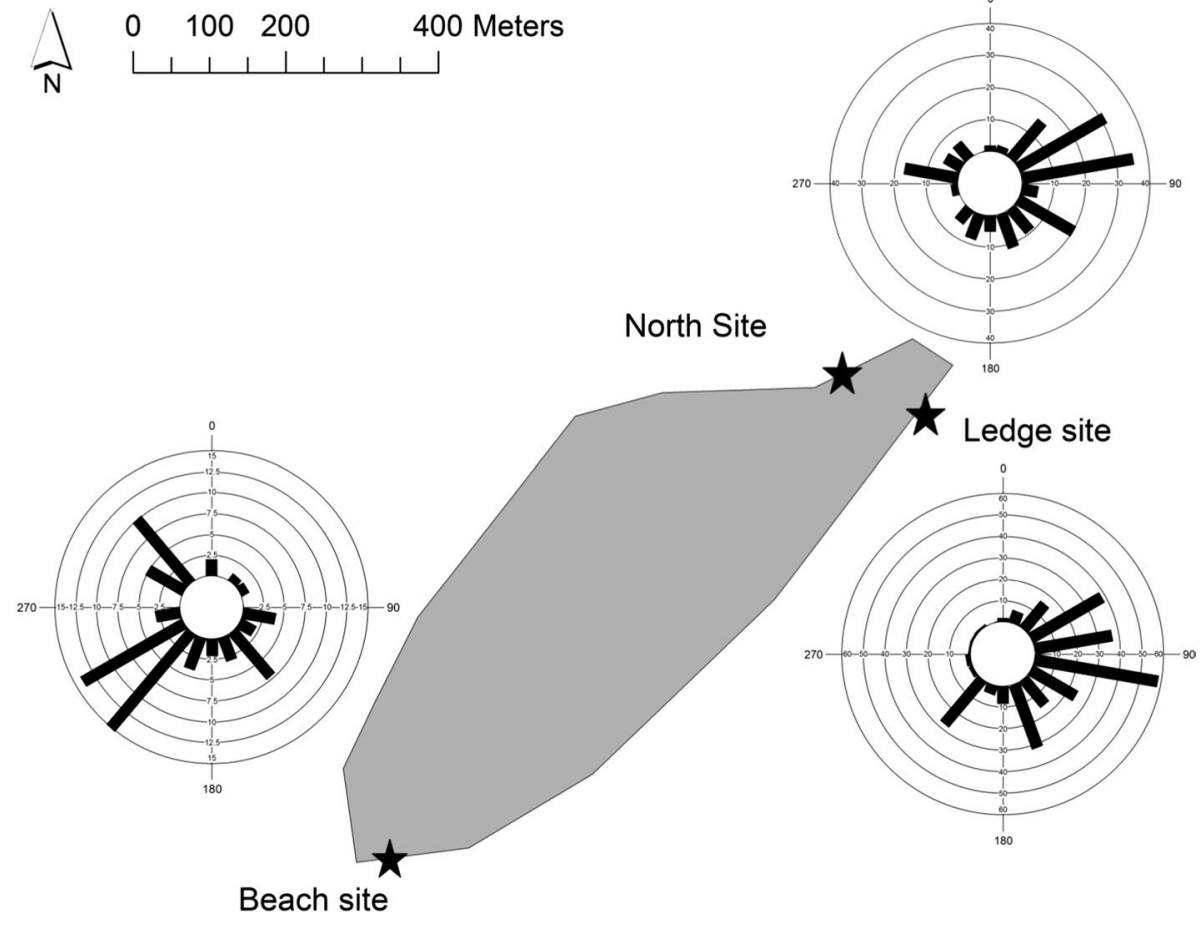

Fig. 6 The effect of different sampling scenarios on European shag foraging trip distance, trip duration, maximum distance travelled from the colony and the area used. Asterisks represent significant differences between groups
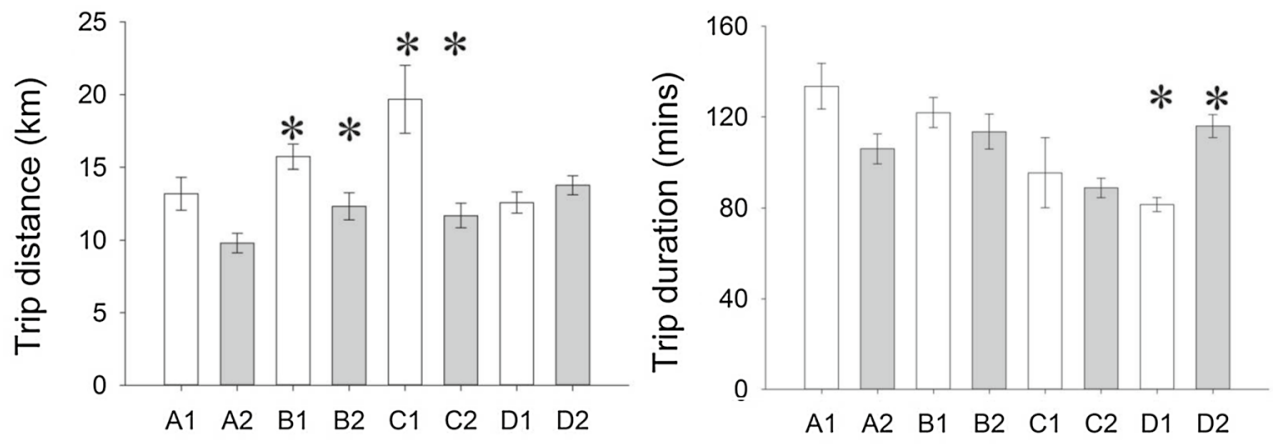

Sampling scenario
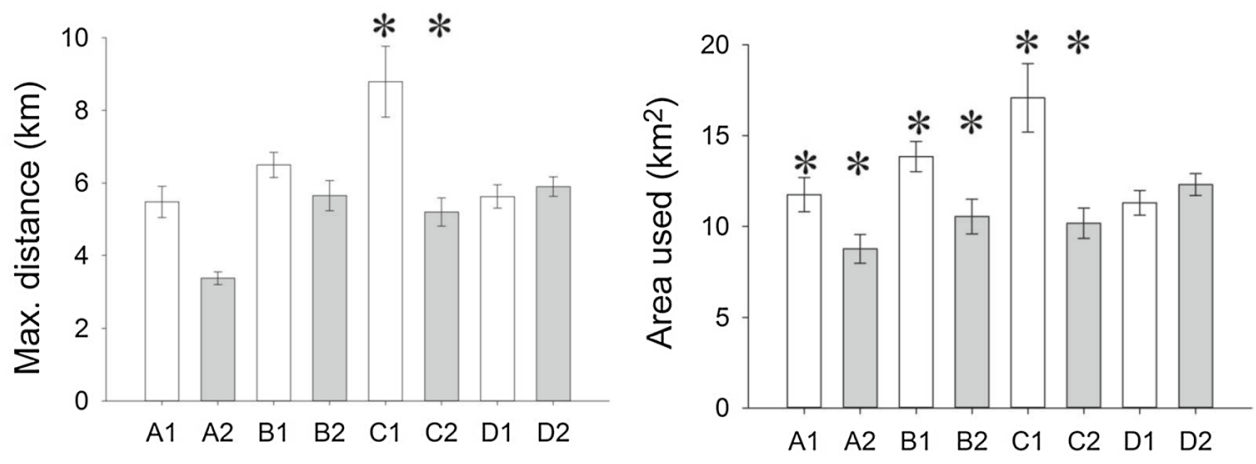

A1 $=1^{\text {st }}-14^{\text {th }}$ May 2010

A2 $=15^{\text {th }}$ May $-14^{\text {th }}$ June 2010

B1= Ledge 2010

C1= Chicks under 14 days 2011

B2 $=$ North side \& beach sites 2010

C2= Chicks over 14 days 2011
D1 $=2011$

D2 $=2012$ 
grypus, and warned that the practice of examining average responses over populations obscures variability in behavioural ecology. Similarly, Antarctic fur seals Arctocephalus gazella were found to exhibit two foraging tactics which were repeatable within an individual (Bonadonna et al. 2001) and Pelagic cormorants P. pelagicus from the same colony were found to have distinct diving patterns (Kotzerka et al. 2011). The degree of individual specialisation varies widely within a population as a result of the diverse array of physiological, behavioural and ecological mechanisms that can act upon an individual (Bolnick et al. 2003). This study conducted over three consecutive field seasons revealed that all five of the foraging trip response variables examined can all be influenced by the explanatory factors included in the GEE model (sex, age of chicks, number of chicks, breeding site, day of season and year of study).

\section{Effect of breeding site}

Breeding site significantly affected total trip duration, the maximum distance travelled from the colony and the area used. Those breeding at the beach site had a reduced foraging trip duration, maximum distance and area compared with those breeding at the North site and the ledge. The direction travelled between these sites was also found to be significantly different. This is an important finding as the logistics of seabird tracking work often means only sub-colonies from any site can or are sampled. Puffin Island is only $1.4 \mathrm{~km}$ long and $0.5 \mathrm{~km}$ at its widest point, but even at this relatively small colony, significant differences in the foraging parameters of shags breeding at different sub-colonies were observed. Similarly, small-scale distribution influenced the parental foraging effort of Tufted puffins Fratercula cirrhata breeding at two sub-colonies only $1.5 \mathrm{~km}$ apart on a single island based on stable isotope analysis (Hipfner et al. 2007). At a larger geographic scale, the foraging behaviour of Gentoo penguins Pygoscelis papua breeding at different sites within the Kerguelen archipelago was found to be more variable that the foraging behaviour observed across the rest of its southern hemisphere range (Lescroel and Bost 2005). Individuals breeding at different sites may represent birds of different status (e.g. younger, inexperienced breeders). For example, the survival of Black-legged kittiwake Rissa tridactyla has been reported to be greater for those nesting in the middle of a colony compared with those on the outskirts, probably related to intrinsically fit and less fit individuals (Aebischer and Coulson 1990). However, European shags have been reported as either selecting nesting sites randomly or that low-quality birds nest preferentially closer to higher quality individuals (Velando and Freire 2001).
No significant differences were found in the number of chicks raised between the sites in this study. Therefore, factors other than individual quality may explain differences in the foraging behaviour at these breeding sites such as bathymetric or oceanographic features around the island (Wienecke and Robertson 2006).

\section{Effect of size of brood}

Total foraging trip distance, trip duration, the maximum distance travelled from the colony and the area used were all significantly affected by the number of chicks an individual was raising. Those raising three chicks made significantly longer trips than those raising one chick. No previously reported studies have related foraging trip characteristics to the number of chicks a seabird is rearing. However, studies have examined parental effort in relation to brood size, and for example, the number of feeding sessions was reported to be significantly greater for Laughing gulls Leucophaeus atricilla rearing three chicks compared with one chick (Gonzalez-Medina et al. 2010). Similarly, Common terns Sterna hirundo, that generally raise three chicks, exhibited a higher rate of food delivery than Arctic terns Sterna paradisaea, which generally raise two chicks, (despite the adults birds being of similar size and morphology), thus indicating that having more chicks resulted in shorter foraging trips (Robinson et al. 2001). This study found individuals raising three chicks made longer foraging trips, perhaps indicating more favourable foraging grounds further from the colony (food limitation close to the colony) or that higher quality individuals had the ability to exploit these better resources and therefore provision for more chicks (Lescroel and Bost 2005; Lescroel et al. 2010).

\section{Effect of sex}

Total trip distance, trip duration and the maximum distance travelled were also significantly affected by sex, with the foraging trips of females covering a greater distance, having a longer duration and being further from the colony than males. Differences in the foraging behaviour between sexes have been widely reported for many seabird species. For example, in Brown boobies Sula leucogaster and Blue-footed boobies Sula nebouxii, both species with reversed sexual dimorphism, females performed longer foraging trips, foraged farther from the colony, flew greater distances and had larger zones of area-restricted search than males (Weimerskirch et al. 2009). Male and female Imperial cormorants $P$. atriceps have also been reported to travel away from their colony using routes virtually perpendicular to each other so that their foraging areas were distinctly different, with females 
foraging close to the coast whilst males foraged offshore in deeper water (Quintana et al. 2011). These studies and the present study represent sexually dimorphic seabirds which could explain the differences observed although studies where males and females are monomorphic have also been reported. For example, female Brunnich's guillemot Uria lomvia were found to forage more during twilight periods and dived shallower than males which foraged primarily during daylight hours (Paredes et al. 2008), sexual differences in the foraging habits and activities have also been reported in the Barau's petrel Pterodroma baraui throughout the breeding period (Pinet et al. 2012). For the sexually dimorphic shag in our study, the smaller females tended on average to travel further and use a larger foraging area than males perhaps reflecting their ability to dive to different depths to exploit prey resources (Quillfeldt et al. 2011; Cook et al. 2007; Kato et al. 2000) or could result from competitive exclusion (Phillips et al. 2011).

\section{Effect of year of study}

The year of study influenced the trip duration but not the other response variables. When comparing 2011 with 2010 and 2012, birds in 2010 travelled similar distances from the colony and the same total distance as the other years but spent longer on foraging trips. The effect of year of study on foraging strategy is predictable given the variability in climatic and weather patterns in any year, which directly relate to sea surface temperature and chlorophyll a abundance which will in turn affect the productivity of the ocean (Fortin et al. 2013). Inter- annual variance in the foraging behaviour of seabirds has often been reported (Chivers et al. 2012; Garthe et al. 2011). However, only 2 out of the 22 studies published between November 2011-November 2012 (Table 1) tracked seabirds for more than one breeding season. Whilst this may not be necessary for the objectives of some studies, for those aiming to identify important foraging ranges and foraging areas, it should be important to consider inter-annual variation given the range of environmental factors that could potentially influence the year of study.

\section{Effect of sampling regimes}

The different hypothetical sampling regimes analysed in this study produced quite different estimates for the foraging trip variables. This study highlights the problem of failing to consider the effects of behavioural, environmental and ecological effects on an individual's foraging behaviour. Drawing inferences to the population as a whole from samples representing a limited spatial, temporal or behavioural scale are unlikely to fully represent the population
(Lindberg and Walker 2007). Whilst previous studies have examined the effects of sample size and sample composition (Morrison 1984; Blundell et al. 2001), few published studies have focused on the composition of samples when examining home-range areas of central-place foragers such as seabirds. Our analysis leads us to recommend that researchers wishing to most accurately identify or delineate home-range areas should ensure that tracking work is conducted throughout the breeding season, between years, and includes both males and females from locations evenly distributed over the field site (rather than concentrating effort in any one area).

Including a larger number of individuals and foraging trips in a sample in any single year will help reduce the influence of variability in foraging trip characteristics caused by factors such as sex, breeding site etc. (Soanes et al. 2013). Indeed, it is this variability that most likely underpins the previously reported relationship between sample size and foraging area size (Soanes et al. 2013). However, as highlighted, samples used in tracking studies are often small. The European shag is a localised coastal feeder, yet even for this relatively short distance forager, the impacts of the explanatory variables were significant on foraging response variable predictions. It is likely that seabirds which have larger foraging radii may exhibit even greater differences in their foraging behaviour in relation to the explanatory variables tested. Therefore, the selection of individuals and timing of tracking for inclusion in tracking studies of any central-place forager are important factors to consider to ensure that the limited samples often used in such studies most accurately predict the colony's foraging characteristics.

Acknowledgments This project was funded by a Doctoral Training Grant from the Natural Environment Research Council, with support from the RSPB's FAME project. We would like to thank Dr. Charles Bishop, Ashley Tweedale, Dr. Rachel Taylor (Bangor University), and volunteers from both the University of Liverpool and Bangor University for assistance with planning and fieldwork. Data collection on Puffin Island would not have been possible without permission to carryout fieldwork from Sir Richard Williams-Bulkeley. Permission was granted by the Countryside Council for Wales to conduct bird capture and tagging work on Puffin Island.

Open Access This article is distributed under the terms of the Creative Commons Attribution License which permits any use, distribution, and reproduction in any medium, provided the original author(s) and the source are credited.

\section{References}

Aebischer NJ, Coulson JC (1990) Survival of the kittiwake in relation to sex, year, breeding experience and position in the colony. $\mathrm{J}$ Anim Ecol 59:1063-1071

Alonso H, Granadeiro JP, Paiva VH, Dias AS, Ramos JA, Catry P (2012) Parent-offspring dietary segregation of Cory's shearwaters breeding in contrasting environments. Mar Biol 159:1197-1207 
Austin D, Bowen WD, McMillan JI (2004) Intraspecific variation in movement patterns: modeling individual behaviour in a large marine predator. Oikos 105:15-30

Batschelet E (1981) Circular statistics in biology. Academic Press, London

Bertrand S, Rocio J, Arbulu Smet C, Tremblay Y, Barbraud C, Weimerskirch $\mathrm{H}$ (2012) Local depletion by a fishery can affect seabird foraging. J Appl Ecol 49:1365-2664

BirdLife International (2010) Marine Important Bird Areas toolkit: standardised techniques for identifying priority sites for the conservation of seabirds at sea. (ed. B. International). Birdlife International, Cambridge, UK

Biro PA, Stamps JA (2010) Do consistent individual differences in metabolic rate promote consistent individual differences in behavior? Trends Ecol Evol 25:653-659

Blundell GM, Maier JAK, Debevec EM (2001) Linear home ranges: effects of smoothing, sample size, and autocorrelation on kernel estimates. Ecol Monogr 71:469-489

Bolnick DI, Svanback R, Fordyce JA, Yang LH, Davis JM, Hulsey CD, Forister ML (2003) The ecology of individuals: incidence and implications of individual specialization. Am Nat 161:1-28

Bonadonna F, Lea MA, Dehorter O, Guinet C (2001) Foraging ground fidelity and route-choice tactics of a marine predator: the Antarctic fur seal Arctocephalus gazella. Mar Ecol Prog Ser 223:287-297

Bugoni L, D'Alba L, Furness RW (2009) Marine habitat use of wintering spectacled petrels Procellaria conspicillata, and overlap with longline fishery. Mar Ecol Prog Ser 374:273-285

Burger AE, Shaffer SA (2008) Application of tracking and data-logging technology in research and conservation of seabirds. Auk 125:253-264

Casper RM, Sumner MD, Hindell MA, Gales NJ, Staniland IJ, Goldsworthy SD (2010) The influence of diet on foraging habitat models: a case study using nursing Antarctic fur seals. Ecography 33:748-749

Chivers LS, Lundy MG, Colhoun K, Newton SF, Houghton JDR, Reid N (2012) Foraging trip time-activity budgets and reproductive success in the black-legged kittiwake. Mar Ecol Prog Ser 456:267-269

Christel I, Navarro J, del Castillo M, Cama A, Ferrer X (2012) Foraging movements of Audouin's gull (Larus audouinii) in the Ebro Delta, NW Mediterranean: a preliminary satellite-tracking study. Estuar Coast Shelf Sci 96:257-261

Cook TR, Cherel Y, Bost CA, Tremblay M (2007) Chick-rearing Crozet shags (Phalacrocorax melanogenis) display sex-specific foraging behaviour. Antarct Sci 19:55-63

Copello S, Quintana F (2009) Spatio-temporal overlap between the at-sea distribution of Southern Giant Petrels and fisheries at the Patagonian Shelf. Polar Biol 32:1211-1220

Daunt F, Wanless S, Harris MP, Money L, Monaghan P (2007) Older and wiser: improvements in breeding success are linked to better foraging performance in European shags. Funct Ecol 21:561-567

De Monte S, Cotte C, d'Ovidio F, Levy M, Le Corre M, Weimerskirch H (2012) Frigatebird behaviour at the ocean-atmosphere interface: integrating animal behaviour with multi-satellite data. J R Soc Int 9:3351-3358

Durant JM, Hjermann DO, Frederiksen M, Charrassin JB, Le Maho Y, Sabarros PS, Crawford RJM, Stenseth NC (2009) Pros and cons of using seabirds as ecological indicators. Clim Res 39:115-129

Eaton M, Brown A, Noble D, Musgrove A, Hearn R, Aebischer N, Gibbons D, Evans A, Gregory R (2009) Birds of conservation concern 3: the population status of birds in the United Kingdom, Channel Islands and the Isle of Man. Br Birds 102:296-341

Elkins N, Williams MR (1974) Shag movements in North-East Scotland. Bird Study 21:149-151
Evans K, Lea MA, Patterson TA (2013) Recent advances in bio-logging science: technologies and methods for understanding animal behaviour and physiology and their environments Introduction. Deep-Sea Res Part Ii-Top Stud Oceano 88-89:1-6

Fort J, Beaugrand G, Gremillet D, Phillips RA (2012) Biologging, remotely-sensed oceanography and the continuous plankton recorder reveal the environmental determinants of a seabird wintering hotspot. PloS One 7:e41194

Fortin M, Bost CA, Maes P, Barbraud C (2013) The demography and ecology of the European shag Phalacrocorax aristotelis in Mor Braz, France. Aquat Living Resour 26:179-185

Frederiksen M, Moe B, Daunt F, Phillips RA, Barrett RT, Bogdanova MI, Boulinier T, Chardine JW, Chastel O, Chivers LS, Christensen-Dalsgaard S, Clement-Chastel C, Colhoun K, Freeman R, Gaston AJ, Gonzalez-Solis J, Goutte A, Gremillet D, Guilford T, Jensen GH, Krasnov Y, Lorentsen S-H, Mallory ML, Newell M, Olsen B, Shaw D, Steen H, Strom H, Systad GH, Thorarinsson TL, Anker-Nilssen T (2012) Multicolony tracking reveals the winter distribution of a pelagic seabird on an ocean basin scale. Divers Distrib 18:530-543

Garthe S, Montevecchi WA, Davoren GK (2011) Inter-annual changes in prey fields trigger different foraging tactics in a large marine predator. Limno Oceanogr 56:802-812

Gonzalez-Medina E, Castillo-Guerrero JA, Mellink E (2010) Parental and chick responses of Laughing Gulls (Leucophaeus atricilla) to increase of flight costs and brood size. J Ornitho 151:687-694

Goddard B (2010) Breeding seabirds on Puffin Island, Anglesey. MSc Thesis, University of Liverpool

Gremillet D, Prudor A, le Maho Y, Weimerskirch H (2012) Vultures of the seas: hyperacidic stomachs in wandering albatrosses as an adaptation to dispersed food resources, including fishery wastes. PloS One 7:37834

Guilford T, Wynn R, McMinn M, Rodriguez A, Fayet A, Maurice L, Jones A, Meier R (2012) Geolocators reveal migration and prebreeding behaviour of the critically endangered balearic shearwater Puffinus mauretanicus. PloS One 7:33753

Harris J, Haward M, Jabour J, Woehler EJ (2007) A new approach to selecting marine protected areas (MPAs) in the Southern Ocean. Antarct Sci 19:189-194

Harris MP, Bogdanova MI, Daunt F, Wanless S (2012) Using GPS technology to assess feeding areas of Atlantic Puffins Fratercula arctica. Ring Migr 27:43-49

Hazen EL, Maxwell SM, Bailey H, Bograd SJ, Hamann M, Gaspar P, Godley BJ, Shillinger GL (2012) Ontogeny in marine tagging and tracking science: technologies and data gaps. Mar Ecol Prog Ser 457:221-240

Hipfner JM, Charette MR, Blackburn GS (2007) Subcolony variation in breeding success in the tufted puffin (Fratercula cirrhata): association with foraging ecology and implications. Auk 124:1149-1157

Højsgaard S, Halekoh U, Yan J (2012) The R package geepack for generalised estimating equations. J Stat Softw 15:1-11

Hyrenbach KD, Keiper C, Allen SG, Ainley DG, Anderson DJ (2006) Use of marine sanctuaries by far-ranging predators: commuting flights to the California Current System by breeding Hawaiian albatrosses. Fish Oceanogr 15:95-103

Jakubas D, Iliszko L, Wojczulanis-Jakubas K, Stempniewicz L (2012) Foraging by little auks in the distant marginal sea ice zone during the chick-rearing period. Polar Biol 35:73-81

Kato A, Watanuki Y, Nishiumi I, Kuroki M, Shaughnessy P, Naito Y (2000) Variation in foraging and parental behavior of King Cormorants. Auk 117:718-730

Kotzerka J, Hatch SA, Garthe S (2011) Evidence for foraging-site fidelity and individual foraging behaviour of pelagic cormorants rearing chicks in the Gulf of Alsaka. Condor 113:80-88 
Langton R, Davies IM, Scott BE (2011) Seabird conservation and tidal stream and wave power generation: information needs for predicting and managing potential impacts. Mar Polar 35:623-630

Lescroel A, Bost CA (2005) Foraging under contrasting oceanographic conditions: the gentoo penguin at Kerguelen Archipelago. Mari Ecol Prog Ser 302(245):261

Lescroel A, Ballard G, Toniolo V, Barton KJ, Wilson PR, Lyver PO, Ainley DG (2010) Working less to gain more: when breeding quality relates to foraging efficiency. Ecology 91:2044-2055

Liang KY, Zeger SL (1986) Longitudinal data-analysis using generalized linear models. Biometrika 73:13-22

Lindberg MS, Walker J (2007) Satellite telemetry in avian research and management: sample size considerations. J Wildl Manage 71:1002-1009

Louzao M, Delord K, Garcia D, Boue A, Weimerskirch H (2012) Protecting persistent dynamic oceanographic features: transboundary conservation efforts are needed for the critically endangered balearic shearwater. PloS One 7:35728

Magnusdottir E, Leat EHK, Bourgeon S, Strom H, Petersen A, Phillips RA, Hanssen SA, Bustnes JO, Hersteinsson P, Furness RW (2012) Wintering areas of great skuas Stercorarius skua breeding in Scotland, Iceland and Norway. Bird Study 59(1):1-9

McLeay LJ, Page B, Goldsworthy SD, Paton DC, Teixeira C, Burch P, Ward T (2010) Foraging behaviour and habitat use of a shortranging seabird, the crested tern. Mar Ecol Prog Ser 411:271-283

Montevecchi W, Fifield D, Burke C, Garthe S, Hedd A, Rail JF, Robertson G (2012) Tracking long-distance migration to assess marine pollution impact. Biol Lett 8:218-221

Morrison ML (1984) Influence of sample-size and sampling design on analysis of avian foraging behaviour. Condor 86:146-150

Moseley C, Gremillet D, Connan M, Ryan PG, Mullers RHE, van der Lingen CD, Miller TW, Coetzee JC, Crawford RJM, Sabarros P, McQuaid CD, Pichegru L (2012) Foraging ecology and ecophysiology of Cape gannets from colonies in contrasting feeding environments. J Exp Mar Biol Ecol 422:29-38

Page B, McKenzie J, Sumner MD, Coyne M, Goldsworthy SD (2006) Spatial separation of foraging habitats among New Zealand fur seals. Mar Ecol Prog Ser 323:263-279

Paredes R, Jones IL, Boness DJ, Tremblay Y, Renner M (2008) Sex-specific differences in diving behaviour of two sympatric Alcini species: thick-billed murres and razorbills. Can J Zool 86:610-622

Perrow MR, Skeate ER, Lines P, Brown D, Tomlinson ML (2006) Radio telemetry as a tool for impact assessment of wind farms: the case of Little Terns Sterna albifrons at Scroby Sands, Norfolk, UK. Ibis 148:57-75

Phillips RA, McGill RAR, Dawson DA, Bearhop S (2011) Sexual segregation in distribution, diet and trophic level of seabirds: insights from stable isotope analysis. Mar Biol 158:2199-2208

Pinet P, Jaquemet S, Phillips RA, Le Corre M (2012) Sex-specific foraging strategies throughout the breeding season in a tropical, sexually monomorphic small petrel. Anim Behav 83:979-989

Quillfeldt P, Schroff S, van Noordwijk HJ, Michalik A, Ludynia K, Masello JF (2011) Flexible foraging behaviour of a sexually dimorphic seabird: large males do not always dive deep. Mar Ecol Prog Ser 428:271-287

Quillfeldt P, McGill RAR, Furness RW, Moestl E, Ludynia K, Masello JF (2012) Impact of miniature geolocation loggers on a small petrel, the thin-billed prion Pachyptila belcheri. Mar Biol 159:1809-1816

Quintana F, Wilson R, Dell'Arciprete P, Shepard E, Gomez Laich A (2011) Women from Venus, men from Mars: inter-sex foraging differences in the imperial cormorant Phalacrocorax atriceps a colonial seabird. Oikos 120:350-358
R Development Core Team (2011) R: A language and environment for statistical computing. R Foundation for Statistical Computing, Vienna, Austria

Ramos R, Granadeiro JP, Nevoux M, Mougin JL, Dias MP, Catry $P$ (2012) Combined spatio-temporal impacts of climate and longline fisheries on the survival of a trans-equatorial marine migrant. PloS One 7:40822

RenewableUK (2011) State of the industry report onshore and offshore wind: progress update. RenewableUK, UK

Robinson JA, Hamer KC, Chivers LS (2001) Contrasting brood sizes in Common and Arctic Terns: the roles of food provisioning rates and parental brooding. Condor 103:108-117

Sala JE, Wilson RP, Frere E, Quintana F (2012) Foraging effort in Magellanic penguins in coastal Patagonia, Argentina. Mar Ecol Prog Ser 464:273-287

Shaffer SA, Tremblay Y, Awkerman JA, Henry RW, Teo SLH, Anderson DJ, Croll DA, Block BA, Costa DP (2005) Comparison of light- and SST-based geolocation with satellite telemetry in freeranging albatrosses. Mar Biol 147:833-843

Snow BK (1963) The behaviour of the shag. Br Birds 56:164-186

Soanes LM, Gauvain RD, Atkinson PW, Green JA (2012) Individual consistency in the foraging behaviour of Northern gannets: implications for interactions with offshore renewable energy developments. Mar Polar 38:505-514

Soanes LM, Arnould JPY, Dodd SG, Sumner MD, Green JA (2013) How many seabirds do we need to define important foraging areas. J Appl Ecol 50(3):671-679

Sommerfeld J, Kato A, Ropert-Coudert Y, Garthe S, Hindell MA (2013) The individual counts: within sex differences in foraging strategies are as important as sex-specific differences in masked boobies Sula dactylatra. J Avian Biol 44:531-540

Stauss C, Bearhop S, Bodey TW, Garthe S, Gunn C, Grecian WJ, Inger R, Knight ME, Newton J, Patrick SC, Phillips RA, Waggitt JJ, Votier SC (2012) Sex-specific foraging behaviour in northern gannets Morus bassanus: incidence and implications. Mar Ecol Prog Ser 457:151-162

Stenhouse IJ, Egevang C, Phillips RA (2012) Trans-equatorial migration, staging sites and wintering area of Sabine's Gulls Larus sabini in the Atlantic Ocean. Ibis 154:42-51

Suarez N, Retana MV, Yorio P (2012) Spatial patterns in the use of foraging areas and its relationship with prey resources in the threatened Olrog's Gull (Larus atlanticus). J Ornith 153:861-871

Sumner M (2012) Package "Trip: Spatial analysis of animal track data". CRAN.r.project.org

Thiebot JB, Cherel Y, Trathan PN, Bost CA (2012) Coexistence of oceanic predators on wintering areas explained by populationscale foraging segregation in space or time. Ecology 93:122-130

Velando A, Freire J (2001) How general is the central-periphery distribution among seabird colonies? Nest spatial pattern in the European Shag. Condor 103:544-554

Wakefield ED, Phillips RA, Belchier M (2012) Foraging black-browed albatrosses target waters overlaying moraine banks-a consequence of upward benthic-pelagic coupling? Antarct Sci 24:269-280

Wakefield ED, Bodey TW, Bearhop S, Blackburn J, Colhoun K, Davies R, Dwyer RG, Green JA, Gremillet D, Jackson AL, Jessopp MJ, Kane A, Langston RHW, Lescroel A, Murray S, Le Nuz M, Patrick SC, Peron C, Soanes LM, Wanless S, Votier SC, Hamer KC (2013) Space partitioning without territoriality in gannets. Science 341:68-70

Wanless S, Harris MP, Morris JA (1991) Foraging range and feeding locations of shags Phalacrocorax-aristotelis during chick rearing. Ibis 133:30-36

Wanless S, Gremillet D, Harris MP (1998) Foraging activity and performance of Shags Phalacrocorax aristotelis in relation to environmental characteristics. J Avian Biol 29:49-54 
Wanless S, Frederiksen M, Daunt F, Scott BE, Harris MP (2007) Black-legged kittiwakes as indicators of environmental change in the North Sea: evidence from long-term studies. Prog Oceanogr 72:30-38

Watanabe YY, Takahashi A, Sato K, Viviant M, Bost CA (2011) Poor flight performance in deep-diving cormorants. J Exp Biol 214:412-421

Weimerskirch H, Shaffer SA, Tremblay Y, Costa DP, Gadenne H, Kato A, Ropert-Coudert Y, Sato K, Aurioles D (2009) Speciesand sex-specific differences in foraging behaviour and foraging zones in blue-footed and brown boobies in the Gulf of California. Mar Ecol Prog Ser 391:267-278

Weimerskirch H, Bertrand S, Silva J, Bost C, Peraltilla S (2012) Foraging in Guanay cormorant and Peruvian booby, the major guano-producing seabirds in the Humboldt Current System. Mar Ecol Prog Ser 458:231

Wienecke B, Robertson G (2006) Comparison of foraging strategies of incubating king penguins Aptenodytes patagonicus from Macquarie and Heard islands. Polar Biol 29:424-438

Wilson RP, Putz K, Peters G, Culik B, Scolaro JA, Charrassin JB, Ropert-Coudert Y (1997) Long-term attachment of transmitting and recording devices to penguins and other seabirds. Wildl Soc Bull 25:101-106

Wilson RP, Gremillet D, Syder J, Kierspel MAM, Garthe S, Weimerskirch H, Schafer-Neth C, Scolaro JA, Bost CA, Plotz J, Nel D (2002) Remote-sensing systems and seabirds: their use, abuse and potential for measuring marine environmental variables. Mar Ecol Prog Ser 228:241-261 